\title{
Significados del acto administrativo en la jurisprudencia de la Corte Constitucional
}

\author{
Meanings of the Administrative Act in the Constitutional Court \\ Jurisprudence \\ Significados do ato administrativo na jurisprudência da Corte \\ Constitucional
}

\section{CRISTIAN ANDrÉs DíAZ DíEZ}

FECHA DE RECEPCIÓN: 17 DE OCTUBRE DE 2018. FECHA DE APROBACIÓN: 28 DE MARZO DE 2019

Doi: http://dx.doi.org/0.12804/revistas.urosario.edu.co/sociojuridicos/a.7807

Para citar este artículo: Díaz Díez, C.A. (2019). Significados del acto administrativo en la jurisprudencia de la Corte Constitucional.Revista Socio-Jurídicos, 21 (2), 259-292. Doi: http://dx.doi.org/0.12804/revistas.urosario.edu.co/ sociojuridicos/a.7807

\section{RESUMEN}

El presente artículo analiza los significados que la Corte Constitucional le ha atribuido a la expresión "acto administrativo", contenida, tanto en su forma singular como plural, en varios enunciados normativos de la Constitución Política de 1991, con la finalidad de concluir si dicha corporación, en ejercicio de su rol de guardiana de la integridad y supremacía de la Constitución, ha construido una definición uniforme del acto administrativo o si, por el contrario, ha utilizado nociones diversas e incluso contradictorias. Así mismo, el artículo se pregunta, ofreciendo una posible respuesta, si de la Constitución puede derivarse la existencia de una definición correcta del acto administrativo, es decir, que más se avenga al contenido de aquella, o si esta es una actividad radicada en el Congreso de la República, en el Gobierno nacional, en la Corte Constitucional o en el Consejo de Estado, los cuales gozan de libertad configuradora para la estructuración de dicho concepto.

Palabras clave: acto administrativo, significado, jurisprudencia, Corte Constitucional, Constitución Política.

* Abogado. Magister en Derecho (modalidad investigación) de la Universidad de Antioquia. Profesor e investigador de planta de Derecho administrativo de la Universidad Eafit, Medellín (Colombia).Correo electrónico: cdiazdi@eafit.edu.co. ORCID: http://orcid.org/0000-0001-91396941. 


\section{ABSTRACT}

This paper analyzes the meanings the Constitutional Court has assigned to the expression "administrative act", contained -both in its singular and plural forms - in several normative statements of the 1991 Political Constitution, with the purpose of concluding if that Corporation, in the exercise of its role as guardian of the Constitutions integrity and supremacy, has built a uniform definition of administrative act or if, on the contrary, it has used diverse and even contradictory notions. Likewise, the paper asks and offers an answer to if the existence of an administrative act's correct definition can be extracted from the Constitution or if defining it, is an activity conferred to the Congress of the Republic, the National Government, the Constitutional Court or the Council of State, which enjoy of configuring freedom for building that concept.

Keywords: Administrative act, meaning, jurisprudence, Constitutional Court, political constitution.

\section{RESUMO}

O presente artigo analisa os significados que a Corte Constitucional lhe tem atribuído à expressão «ato administrativo», contida -tanto em sua forma singular, quanto plural- em vários enunciados normativos da Constituição Política de 1991, com a finalidade de concluir se dita Corporação, em exercício de seu papel de guardiã da integridade e supremacia da Constituição, tem construído uma definição uniforme de ato administrativo ou se, pelo contrário, tem utilizado noções diversas, inclusive contraditórias. Da mesma forma, o artigo pergunta-se, oferecendo uma possível resposta, se da Constituição pode derivar-se a existência de uma definição correta do ato administrativo, é dizer, que mais se adequa ao conteúdo daquela, ou se esta é uma atividade radicada no Congresso da República, no Governo Nacional, na Corte Constitucional ou no Conselho de Estado, os quais gozam de liberdade configuradora para a estruturação de dito conceito.

Palavras-chave: ato administrativo, significado, jurisprudência, Corte Constitucional, Constituição Política. 


\section{Introducción}

Desde hace siglos, dentro de las formas de ejercicio de la función administrativa, el acto administrativo ha ocupado un lugar preeminente, cumpliendo una doble función: i) consolidar el Derecho administrativo, como régimen jurídico especial, y ii) delimitar el alcance del control jurisdiccional a la actuación de las autoridades.

Frente a la primera función, a pesar de que hoy no puede afirmarse esto de una forma tan contundente, se ha señalado que el acto administrativo es la institución capital o más definitoria del Derecho administrativo, porque las autoridades administrativas se expresan, en gran medida, a través de dicha modalidad de conducta y, además, porque el acto administrativo dota de "fijeza" o seguridad jurídica la relación entre la Administración y los particulares (Bocanegra, 2005, pp. 17-18).

En cuanto a la segunda función, bien es sabido que el contenciosoadministrativo se estructuró, en sus orígenes, como un "proceso al acto" (García de Enterría, 2007, p. 52), es decir, que la competencia jurisdiccional para llevar a cabo el control de legalidad sobre la actuación de la Administración solo se activaba cuando se demostraba que esta había expedido un acto administrativo. Tal era la idea que inspiraba el recurso por exceso de poder, así como la clásica distinción francesa entre actos de gestión y actos de autoridad. Con el tiempo, esta necesidad de acreditar la existencia de un acto administrativo, como presupuesto del control jurisdiccional cedió paso a una concepción integral de la tutela judicial efectiva, que, en un Estado constitucional y democrático de Derecho, debe recaer sobre cualquier forma de conducta administrativa -hechos, omisiones, operaciones, contratos y vías de hecho- y no solo frente a actos administrativos. Sin embargo, subsisten medios de control judicial que enjuician la legalidad del acto administrativo, como el de nulidad simple, el de nulidad y restablecimiento del derecho y el de nulidad electoral, entre otros, lo que hace que el concepto de acto administrativo mantenga su función delimitadora de la competencia jurisdiccional y que convenga preguntarse cuál es la definición de dicha figura dentro del ordenamiento jurídico.

La Constitución Política de 1991, en tres disposiciones, hace referencia al concepto de acto administrativo: por un lado, el artículo 87 establece que "It]oda persona podrá acudir ante la autoridad judicial para hacer 
efectivo el cumplimiento de una ley o un acto administrativo", consagrando así la denominada acción de cumplimiento, como mecanismo judicial que, según se lee, procede tanto sobre leyes como sobre los actos administrativos.

Por otra parte, el artículo 238 prevé que "[l]a jurisdicción de lo contencioso administrativo podrá suspender provisionalmente, por los motivos y con los requisitos que establezca la ley, los efectos de los actos administrativos que sean susceptibles de impugnación por vía judicial". Como se observa, en esta disposición, el término "actos administrativos" se usa para indicar que sobre ellos procede la medida cautelar de suspensión provisional.

De otro lado, el artículo 277 numeral 1, le atribuye al Procurador General de la Nación, por sí o por medio de sus delegados y agentes, "[v]igilar el cumplimiento de la Constitución, las leyes, las decisiones judiciales y los actos administrativos".

Por último, una cuarta disposición, el artículo 189 numeral 12, a pesar de que no utiliza la expresión exacta, al hacer alusión a las funciones del Presidente de la República como Jefe de Estado, Jefe de Gobierno y Suprema Autoridad Administrativa, dice que este debe "[p]resentar un informe al Congreso, al iniciarse cada legislatura, sobre los actos de la Administración".

Con el término "actos de la administración", el enunciado normativo se refiere a los actos administrativos, aunque de manera imprecisa.

De allí surge la siguiente pregunta: ¿existe un concepto constitucional de acto administrativo? Esto es, ¿hay un significado correcto de dicho término, desde una perspectiva constitucional?

Como no se evidencia en el articulado de la Constitución una definición del acto administrativo, conviene preguntarse, si la respuesta a los anteriores interrogantes es afirmativa, iquién goza de competencia, o sea, de habilitación constitucional, para determinar el sentido de dicho concepto? ¿El legislador, el Gobierno nacional en ejercicio de su potestad reglamentaria, la Corte Constitucional o el Consejo de Estado?

El objetivo del presente artículo es examinar si en la jurisprudencia de la Corte Constitucional hay una definición del acto administrativo que permita afirmar la existencia de un significado que más se avenga con la Constitución o si, por el contrario, no hay un concepto claro sobre dicha figura en el conjunto de providencias de este alto tribunal. 
Para construir este texto se realizó una búsqueda de providencias de la Corte Constitucional mediante su sistema de relatoría, sin delimitación temporal, que abordaran el concepto de acto administrativo, o sea, que aludieran a su significado (en forma implícita o explícita) y no simplemente mencionaran el término. Si bien los órganos de la Jurisdicción de lo Contencioso Administrativo -en especial el Consejo de Estado- han elaborado a través de su jurisprudencia definiciones de dicha institución, se consideró pertinente indagar de manera preferente en esta oportunidad por los usos que la Corte Constitucional le ha otorgado a tal concepto, teniendo en cuenta que el artículo 241 de la Carta le confiere "la guarda de la integridad y supremacía de la Constitución". En tal medida, adquiere relevancia preguntarse si al interpretar autorizadamente la Constitución, la Corte ha definido de manera uniforme el acto administrativo o si los significados que le ha asignado a dicha forma de actuación de las autoridades han sido divergentes.

\section{Definiciones del acto administrativo construidas por la Corte Constitucional}

Ante la ausencia de una definición del acto administrativo en la Constitución, la Corte Constitucional, en varias sentencias, se ha encargado de adaptar una noción doctrinaria o de construir un significado de aquél. A continuación, se efectúa un análisis cronológico de dichos pronunciamientos, intentando determinar si, a partir de los mismos, es posible estructurar una noción común admitida por dicha corporación, en su labor de interpretación de las disposiciones constitucionales que utilizan la expresión acto administrativo.

\section{Sentencia C-487/1996: las declaraciones de juicio, de conocimiento o de deseo, no son actos administrativos, pero en algunos casos sí}

Entre los primeros pronunciamientos de la Corte Constitucional sobre el alcance del concepto de acto administrativo debe mencionarse la Sentencia C-487/1996 (M.P. Antonio Barrera Carbonell), que contiene la decisión sobre la demanda de inconstitucionalidad parcial contra el 
artículo 264 de la Ley 223 de 1995 "por la cual se expiden normas sobre racionalización tributaria y se dictan otras disposiciones"; enunciado que establece, pues fue declarado exequible en aquella oportunidad y no ha sido derogado, que los conceptos de la Subdirección Jurídica de la Dirección de Impuestos y Aduanadas Nacionales son vinculantes.

Para el demandante, la frase "[d]urante el tiempo en que tales conceptos se encuentren vigentes, las actuaciones tributarias realizadas a su amparo no podrán ser objetadas por las autoridades tributarias (Corte Constitucional de Colombia, 1996 [en línea]), contenida en dicho artículo, era contraria a los artículos 6, 150 y 189 numeral 11 de la Constitución Política y, en tal sentido, debía declararse inexequible, porque le otorgaba una potestad normativa a la Dirección de Impuestos y Aduanas Nacionales, desconociendo que esta competencia solo recae, según la Constitución, en el Congreso y en el Presidente de la República. Por tal razón, en su sentir, dichos conceptos no podían ser vinculantes para las autoridades administrativas y jurisdiccionales.

Con la finalidad de emitir un pronunciamiento de fondo sobre los cargos de la demanda, la Corte analiza, en términos generales, las distintas formas de la actividad administrativa dentro del Estado social de Derecho, indicando que

[ell acto administrativo, constituye el modo de actuación jurídica ordinaria de la administración, y se manifiesta a través de las declaraciones unilaterales, creadoras de situaciones jurídicas generales, objetivas y abstractas, o subjetivas particulares y concretas que reconocen derechos o imponen obligaciones a los administrados. (Corte Constitucional de Colombia, 1996, [en línea])

Por tanto, para poder considerar una declaración como un acto administrativo, esta debe expresar la decisión de producir efectos jurídicos, es decir, la intención de crear (hacer surgir), modificar (variar) o extinguir (finiquitar) un derecho o una obligación (de dar, hacer o no hacer).

En consecuencia, la Corte sostiene, citando a George Vedel, que no son actos administrativos aquellos que solo expresan juicio, deseo o querer, pero que no contienen, materialmente, una decisión, como sucede con los dictámenes o informes que sirven de fundamento para 
resolver un caso, al igual que con los conceptos. Para el alto tribunal, estos "no constituyen, en principio, una decisión administrativa, es decir, una declaración que afecte la esfera jurídica de los administrados, en el sentido de que se les imponga mediante ellos deberes u obligaciones o se les otorgue derechos" (Corte Constitucional de Colombia, 1996, len línea]), pues tales conceptos dejan libre a su destinatario de acogerlos o no; es decir, no son vinculantes. Sin embargo, la Corte aclara que cuando el concepto autorregula la actividad administrativa o es obligatorio para terceros, asume un carácter decisorio que permite considerarlo como un acto administrativo.

Estas precisiones le permiten a la Corte concluir que si bien, en principio, los conceptos emitidos por la Subdirección Jurídica de la Dirección de Impuestos y Aduanas Nacionales no son actos administrativos -porque solo expresan la manifestación de juicio o conocimiento sobre la interpretación de las normas jurídicas tributarias, aduaneras o cambiarias; es decir, no tienen un carácter decisorio-, podrían convertirse en actos administrativos de tipo reglamentario, cuando revistan fuerza vinculante para las autoridades o los administrados.

La Corte declara la constitucionalidad del aparte normativo demandado, porque considera que los principios de buena fe y confianza legítima sustentan la idea de que las actuaciones tributarias realizadas al amparo de un concepto emanado de la Subdirección Jurídica de la Dirección de Impuestos y Aduanas Nacionales no pueden objetarse mientras este se encuentre vigente. Además, señala que en aquellos casos en los que tales conceptos adquieran fuerza vinculante y, como se dijo, se transformen en actos administrativos, ostentan la naturaleza de reglamentos, pero se ubican en un nivel de la pirámide normativa inferior a los decretos reglamentarios expedidos por el presidente de la República en ejercicio de la potestad conferida por el artículo 189 numeral 11 de la Constitución. Por tal razón, el artículo 264 de la Ley 223 de 1995 no implica una usurpación por parte de la Dirección de Impuestos y Aduanas Nacionales de las competencias normativas atribuidas por la Constitución al Congreso y al presidente de la República.

En conclusión, la Corte Constitucional en este fallo diferencia los conceptos y los actos administrativos, a partir de un criterio: el carácter vinculante de estos, a diferencia del sentido meramente orientador $\mathrm{o}$ 
indicativo de aquellos. Si bien acepta que las declaraciones de juicio o de "querer" no pueden considerarse, en principio, actos administrativos, admite que si de dichas manifestaciones se desprenden efectos jurídicos (creación de derechos o de obligaciones), estas mutan a actos administrativos. En otras palabras, bajo este entendimiento, el acto administrativo es una declaración de voluntad (decisoria), de juicio o de deseo, productora de efectos jurídicos.

\section{Sentencia C-638/2000: alcance de la expresión "actos administrativos» en relación con la procedencia de la acción de cumplimiento}

En la Sentencia C-638/2000 (M.P. Vladimiro Naranjo Mesa), la Corte Constitucional resuelve la demanda presentada, en ejercicio de la acción pública de inconstitucionalidad, en contra del artículo 24 de la Ley 393 de 1997, “[plor la cual se desarrolla el artículo 87 de la Constitución Política, referido a la acción de cumplimiento". Como se indicó al comienzo, esta norma constitucional dispone que dicha acción procede para garantizar que se cumplan las leyes y los actos administrativos. El enunciado normativo demandado estableció: "La Acción de Cumplimiento no tendrá fines indemnizatorios. Cuando del incumplimiento de la Ley o de actos administrativos se generen perjuicios, los afectados podrán solicitar las indemnizaciones por medio de las acciones judiciales pertinentes" (Congreso de la República de Colombia, 1997, [en línea]).

Para el demandante, esta norma debía declararse inexequible, porque, al no permitir que se obtuviera la indemnización de los perjuicios ocasionados por el acto administrativo, a través del ejercicio de la acción de cumplimiento, vulneraba los artículos 2, 5, 53, 84, 87, 90, 93 y 95 numeral 7 de la Constitución Política, comprometiendo la eficacia de la administración de justicia, la indemnidad patrimonial de las personas, la economía, la celeridad y la prevalencia de lo sustancial sobre lo procedimental, entre otros principios, ya que una persona se vería obligada a entablar dos procesos, si quisiera el cumplimiento del acto administrativo y la indemnización de perjuicios, congestionando así la administración de justicia.

La Corte declara constitucional el primer inciso del artículo y se considera inhibida para fallar de fondo respecto de su segundo inciso. El fundamento de la ratificación de la constitucionalidad del primer enunciado 
normativo fue que la acción de cumplimiento se encuentra consagrada como un trámite breve y ad hoc, para obtener el cumplimiento de las leyes y de los actos administrativos, razón por la cual incluir en ella la pretensión de declaratoria de responsabilidad y de condena a la indemnización de perjuicios terminaría dilatando el proceso y desnaturalizando su sentido. Además, en palabras de la Corte, el legislador goza de libertad de configuración normativa de los procesos judiciales.

Para llegar a esta conclusión, la Corte precisa las características de la acción de cumplimiento, indicando al respecto que su objeto es lograr la eficacia de una ley o de un acto administrativo. En cuanto a la ley, expresa que dicha acción procede frente a leyes en sentido formal o material. En lo que se refiere al acto administrativo, señala que este también puede ser objeto de la acción de cumplimiento - tal como lo autoriza la Constitución y la ley-, siempre que se trate de un acto administrativo general, pues este es asimilable, materialmente, a una ley, porque contiene una norma de carácter general, impersonal y abstracto. También indica que para obtener la eficacia de los actos administrativos de carácter particular o concreto no resulta inconstitucional que el legislador consagre otros mecanismos judiciales en el ordenamiento jurídico, distintos a la acción de cumplimiento, de donde se interpreta que este trámite procesal no es procedente para garantizar la ejecución de lo ordenado en dichos actos.

Sin embargo, al determinar el alcance de la expresión "actos administrativos", prevista en el artículo 87 de la Constitución Política, en tanto disposiciones susceptibles de la acción de cumplimiento, la Corte Constitucional no construye concepto alguno, es decir, no define la figura, sino que, según se anotó, se ampara en la distinción entre actos administrativos de contenido general y de contenido particular, para indicar que dicha acción procede frente a los primeros. En otros términos, la Corte aplica uno de los criterios de clasificación del acto administrativo, pero no hace explícito el significado de esta institución.

\section{Sentencia C-037/2000: los reglamentos son actos administrativos, pero no todo acto administrativo es un reglamento}

El mismo año de la sentencia analizada previamente, la Corte conoció la demanda de inconstitucionalidad presentada por un ciudadano en 
contra de los artículos 240 de la Ley $4^{\text {a }}$ de 1913 y 12 de la Ley 153 de 1887, que disponían que si se presentaba contradicción entre los actos normativos, tanto a nivel nacional como territorial, había un orden de preferencia, en virtud del cual prevalecía la ley sobre el reglamento y este sobre las demás órdenes de los superiores, de donde se derivaba la posibilidad de inaplicar los actos que vulneraran las normas superiores y la "doctrina legal más probable".

En sentir del demandante, estas disposiciones contravenían los artículos 113, 116, 121, 237, 238 y 240 de la Constitución Política, porque desconocían que la Jurisdicción de lo Contencioso Administrativo es la única competente para hacer cesar la eficacia de los actos administrativos y, en tal sentido, pasaban por alto la presunción de legalidad de los mismos, que resulta contradictoria con la posibilidad de que los funcionarios de la Administración apliquen la excepción de ilegalidad de tales actos.

Mediante la Sentencia C-037/2000 (M.P. Vladimiro Naranjo Mesa), la Corte se pronuncia sobre estos cargos, declarando la inexequibilidad del artículo 240 de la Ley $4^{\text {a }}$ de 1913 y de las expresiones "expedidos en ejercicio de la potestad reglamentaria" y "ni a la doctrina legal más probable", contenidas en el artículo 12 de la Ley 153 de 1887. Como sustento de su decisión, sostiene que de la Constitución Política emana una jerarquía normativa, que se aprecia en varios de sus postulados; prelación que surge, o bien en virtud de la materia regulada o de la ubicación de la autoridad que expide el acto en la estructura del Estado.

A pesar de que hace esta consideración especial sobre los actos administrativos, para la Corte resulta admisible la excepción de ilegalidad, es decir, la inaplicación de actos normativos que sean contrarios a los superiores, pues, de acuerdo con el alto tribunal, esta es una consecuencia del principio de jerarquía normativa que se deduce de la Constitución. Sin embargo, para la Corte, del artículo 238 de la Constitución se desprende una reserva constitucional en cabeza de la Jurisdicción de lo Contencioso Administrativo para pronunciarse sobre la legalidad de los actos administrativos y, en tal sentido, solo ella puede declarar, de oficio o a petición de parte, la excepción de ilegalidad de estos.

Ahora bien, en este fallo la Corte Constitucional no adopta tampoco una definición del acto administrativo. A pesar de que utiliza dicho concepto en varios apartados, lo hace suponiendo un significado. Es más, en el 
numeral 9 de la sentencia realiza una precisión terminológica, para indicar que las expresiones "orden del superior" u "órdenes de los superiores", "reglamento ejecutivo", "reglamentos del gobernador" y "reglamentos del alcalde", contenidas en el artículo 240 de la Ley $4^{\text {a }}$ de 1913, resultaban ambiguas y confusas, porque no abarcaban todos los actos administrativos que pueden expedir dichas autoridades. Y es esto lo que conduce a la Corte a concluir "que la terminología empleada por la norma en comento no se adecúa al sistema de fuentes que consagra la Constitución Política y que ha sido objeto de análisis a lo largo de esta Sentencia, por lo cual debe declararla inexequible" (Corte Constitucional de Colombia, 2000, [en línea]).

Algo similar lleva a cabo la Corte, en relación con el artículo 12 de la Ley 153 de 1887, cuya terminología también considera desactualizada. En tal sentido, plantea que no puede afirmarse que solo los actos ejecutivos o expedidos en ejercicio de la potestad reglamentaria están supeditados a la ley, pues esta es una exigencia de todos los actos administrativos.

Por tanto, si bien la sentencia no expresa cuál es el significado del concepto "acto administrativo", aplica la consecuencia de una definición implícita en el contenido del fallo: que todos los reglamentos, órdenes de gobierno o de superiores de la Administración y actos ejecutivos, son especies de actos administrativos, pero que esta es una categoría más amplia, que abarca otras manifestaciones, y que siempre debe sujetarse al principio de jerarquía normativa, emanado de la Constitución. Dicho de otro modo, todos los reglamentos son actos administrativos, pero no todos los actos administrativos son reglamentos.

\section{Sentencia C-1436/2000: el acto administrativo es una institución delimitadora de competencia jurisdiccional}

En la Sentencia C-1436 /2000 (M.P. Alfredo Beltrán Sierra), la Corte Constitucional resolvió la demanda formulada contra los artículos 70 y 71 de la Ley 80 de 1993, declarando su exequibilidad condicionada, bajo el entendido de que los tribunales de arbitramento constituidos para resolver las controversias derivadas de un contrato estatal no tienen competencia para pronunciarse sobre la validez de los actos administrativos proferidos en ejercicio de poderes excepcionales. 
Los artículos 70 y 71 de dicha ley establecían que en los contratos estatales podían pactarse cláusulas compromisorias, para someter a tribunales de arbitramento las distintas controversias contractuales.

En criterio del demandante, tales disposiciones eran contrarias a los artículos 29, 116, 236, 237 y 238 de la Constitución Política, porque vulneraban el derecho fundamental al debido proceso, pues desconocían que la Jurisdicción de lo Contencioso Administrativo es el juez natural de los actos administrativos, o sea, la única autoridad judicial que puede pronunciarse sobre la legalidad de los mismos, quedándole esto proscrito a los árbitros, aun cuando los actos administrativos sean contractuales.

Como respuesta a este cargo, la Corte Constitucional parte por considerar que los árbitros son particulares que administran justicia en forma limitada -temporal y materialmente-, pues solo pueden pronunciarse sobre asuntos susceptibles de transacción. En tal sentido, advierte que aquellos no pueden juzgar aspectos relativos a normas de orden público. Por lo tanto, se pregunta si los árbitros están habilitados para controlar la legalidad de los actos administrativos.

Para resolver este interrogante que, tal como se indicó, constituyó el problema jurídico central de la demanda, la Corte define el acto administrativo, siendo la primera sentencia en la que el alto tribunal opta por una definición explícita, pues las anteriores supusieron el concepto o hicieron referencia a alguna de las tipologías del acto administrativo, pero no afirmaron un significado concreto; ni siquiera la Sentencia C-487/1996-. En efecto, el máximo tribunal expresa que el acto administrativo puede definirse como "la manifestación de la voluntad de la administración, tendiente a producir efectos jurídicos ya sea creando, modificando o extinguiendo derechos para los administrados o en contra de éstos" (Corte Constitucional de Colombia, 2000, [en línea]).

De la definición acogida por la Corte se destacan varios elementos: i) considera que el acto administrativo es una manifestación de voluntad, es decir, un producto intelectual y no una actuación material; ii) sostiene que tal manifestación volitiva debe tener la vocación de producir efectos jurídicos; con lo cual excluye del concepto de acto administrativo aquellas declaraciones no destinadas a generarlos; iii) entiende la producción de efectos jurídicos como la creación, la modificación o la extinción de derechos o de deberes para los administrados, reconociendo así el 
contenido favorable o desfavorable del acto, aunque dejando por fuera del concepto la generación de efectos jurídicos ad-intra, esto es, al interior de la Administración, sin que se causen o afecten derechos u obligaciones para los administrados. Obsérvese, además, que en la definición la Corte prescinde de dos elementos - $\mathrm{O}$, por lo menos, no los menciona-: el necesario carácter unilateral de la manifestación de voluntad y la función que debe ejercer la Administración para que el acto pueda considerarse acto administrativo, no exigiendo que deba tratarse de la función administrativa.

Con fundamento en las consideraciones expuestas, la Corte Constitucional expresa con claridad que los particulares, en su calidad de árbitros, no están facultados para emitir un juicio de validez de los actos administrativos -como, por ejemplo, sobre los actos que hacen efectivas las cláusulas excepcionales en la contratación estatal-, ni definitivo, ni por la vía de la suspensión provisional, porque esta es una competencia exclusiva de la Jurisdicción de lo Contencioso Administrativo; lo que no obsta para que aquellos se pronuncien sobre los efectos económicos de los actos administrativos, pues, al ser este un asunto susceptible de transacción, ingresa, materialmente, dentro de la habilitación que les confiere la Constitución y la ley para administrar justicia.

\section{Sentencia C-620/2004: la decisión de nombramiento de jurados de votación es un acto administrativo}

En 2004, la Corte resuelve una demanda de inconstitucionalidad parcial contra el artículo 105 del Decreto 2241 de 1986, que, en lo pertinente, establecía que "[e]l cargo de jurado de votación es de forzosa aceptación, y la notificación de tales nombramientos se entenderá surtida por la sola publicación o fijación en lugar público de la lista respectiva, (...)" (Gobierno de la República de Colombia, 1986, len línea]), pues, según el demandante, esta prescripción vulneraba los artículos 1, 2, 6, 29 y 95 de la Constitución, en la medida en que imponía una sanción por un deber frente al cual no existía garantía de conocimiento efectivo por parte de los ciudadanos, pues la fijación de la lista de los jurados en lugares públicos no es razonable, ni proporcional, es decir, no satisface la exigencia de publicidad que debe regir en un Estado social de Derecho y atenta contra la dignidad humana. 
Para fallar, la Corte analiza la naturaleza jurídica del acto de nombramiento del jurado de votación y la forma como debe cumplirse su publicidad. En tal sentido, afirma que se trata de un acto administrativo, fundamentando esta postura en la idea de que este es "Il]a declaración de voluntad, de juicio, de conocimiento o de deseo realizada por la administración en ejercicio de una potestad administrativa distinta de la potestad reglamentaria (cursiva en la cita original)" (Corte Constitucional de Colombia, 2004, [en línea]), acogiendo textualmente la definición ofrecida por Eduardo García de Enterría y Tomás-Ramón Fernández en su Curso de Derecho administrativo. Además, indica que el nombramiento de los jurados de votación es un acto administrativo de carácter particular y concreto, porque en él se realiza una individualización de sus destinatarios y se establecen unos deberes específicos y claros. ${ }^{1}$

1 La Corte Constitucional también utilizó la definición de acto administrativo de Eduardo García de Enterría y Tomás-Ramón Fernández en la Sentencia T-945 de 2009 (M.P. Mauricio González Cuervo), en la que señaló que las decisiones proferidas dentro de un concurso de méritos, antes de que se adopte la decisión final, son actos administrativos de trámite. Así mismo, en esta sentencia la Corte retomó la diferencia entre los actos administrativos de carácter general y los de carácter particular, manteniendo las consideraciones de la Sentencia C-620/2004. Ahora bien, al definir los actos administrativos de trámite, sostuvo que estos "no expresan en concreto la voluntad de la administración", sino que "simplemente constituyen el conjunto de actuaciones intermedias que preceden a la formación de la decisión administrativa que se plasma en el acto definitivo y en la mayoría de los casos no crean, modifican o extinguen situaciones jurídicas", razón por la cual, agrega, "contra los actos de trámite la acción de tutela procede de manera excepcional cuando el respectivo acto tiene la potencialidad de definir una situación especial y sustancial dentro de la actuación administrativa y ha sido fruto de una actuación abiertamente irrazonable o desproporcionada del funcionario, con lo cual vulnera las garantías establecidas en la Constitución". Esta definición del acto administrativo de trámite es incoherente con el concepto de acto administrativo de Eduardo García de Enterría y Tomás-Ramón Fernández, que se defiende, tanto en este fallo, como en la Sentencia C-620/04, pues si el acto administrativo de trámite no es una manifestación de voluntad y no produce efectos jurídicos, sencillamente, no podría considerarse un acto administrativo. Sin embargo, no fue esto lo que quiso indicar la Corte. Tanto es así, que, expresamente, señala que los actos de trámite son una de las tipologías de acto administrativo, que se diferencian de los actos administrativos definitivos. Pero la contradicción de la definición es evidente. Una cosa es que el acto administrativo de trámite no resuelve el fondo del procedimiento administrativo y que, en tal medida, haya restricciones a su impugnabilidad, y otra cosa es afirmar que no exprese una voluntad de la Administración o que no cree, modifique o extinga situaciones jurídicas (derechos u obligaciones). Basta pensar, por ejemplo, en el acto que decreta o niega la práctica de una prueba o el que ordena citar a los terceros interesados en el trámite para que, si a bien lo consideran, hagan valer su derecho. Negar que en estas decisiones haya voluntad administrativa y que se afecte (positiva o negativamente) una situación jurídica, es equivocado. Sin embargo, infortunadamente, la Corte Constitucional ha mantenido este criterio. Al respecto, véase las sentencias SU-617 de 2014 (M.P. Nilson Pinilla Pinilla), T-533 de 2014 (M.P. Luis Guillermo Guerrero Pérez) y T-412 de 2017 (M.P. Gloria Stella Ortiz Delgado). 
Ahora bien, refiriéndose al reproche jurídico formulado por el actor, la Corte Constitucional llega a la conclusión de que, a pesar de ser el acto de nombramiento de jurados electorales un acto administrativo de carácter particular o concreto, y de que la notificación personal es, por excelencia, la forma de garantizar la publicidad de este tipo de actos, en el caso de aquel, no existe vicio de inconstitucionalidad alguno en que el legislador haya establecido una forma sui generis de notificación no personal, sino a través de la fijación de la lista de los jurados nombrados, en un lugar público; instrumento que, por el contrario, la Corte considera razonable y proporcional. Pero, a pesar de esta afirmación, condiciona la constitucionalidad del enunciado normativo, a que se entienda que el lugar de fijación de la lista debe ser, en efecto, público para la ciudadanía, especialmente para quienes podrían ser nombrados.

Como puede apreciarse, en este caso la Corte acude a una noción doctrinaria de acto administrativo, con un carácter instrumental, para determinar si el mecanismo de publicidad de la decisión de una autoridad respetaba o no los principios constitucionales y los derechos fundamentales de sus destinatarios. Sin embargo, la máxima corporación no desarrolla los elementos de la definición que utiliza; aunque, con su citación textual, podría concluirse que la acoge completamente. Así pues, mientras que en el 2000, según se indicó, este tribunal había planteado que el acto administrativo es una manifestación de voluntad y que el reglamento era un tipo de acto administrativo, en esta ocasión, de la mano de García de Enterría y Fernández, concluyó que es una "declaración de voluntad, de juicio, de conocimiento o de deseo" (Corte Constitucional de Colombia, 2004, [en línea]). Los conceptos "manifestación" y "declaración" no necesariamente coinciden o son expresiones sinónimas. Por otra parte, al admitir que la declaración pueda ser, además de voluntad, de juicio, de conocimiento o de deseo, con ello se amplía el rango del concepto de acto administrativo, porque, por ejemplo, los informes o conceptos terminan ingresando dentro de dicha categoría. Adicionalmente, sostener que la potestad que debe ejercer la Administración para expedir un acto administrativo es una función administrativa, distinta de la potestad reglamentaria, implica aceptar, entonces, que los reglamentos no son actos administrativos, lo que riñe con la concepción mayoritaria de la jurisprudencia contencioso-administrativa y de la doctrina que hay 
sobre la materia en Colombia, que, casi de manera unánime, ha reconocido que el reglamento es una especie de acto administrativo general, caracterizada por su vocación de permanencia en el tiempo. A su vez, la Corte en este fallo no destaca la producción de efectos jurídicos como elemento de la definición del acto administrativo.

\section{Sentencia C-542/2005: los actos administrativos son distintos a los conceptos de la Administración, porque aquellos son obligatorios}

La Sentencia C-542/2005 (M.P. Humberto Antonio Sierra Porto) se expidió para decidir la demanda de inconstitucionalidad invocada en forma parcial contra el artículo 25 del Decreto 01 de 1984 (Código Contencioso Administrativo), frente al acápite que establecía que las respuestas a las consultas formuladas en ejercicio del derecho de petición "no comprometerán la responsabilidad de las entidades que las atienden, ni serán de obligatorio cumplimiento o ejecución" (Gobierno de la República de Colombia, 1984, [en línea]).

Las expresiones respecto de las cuales se solicitó su declaratoria de inexequibilidad fueron las palabras "no" y " $\mathrm{ni}^{\text {", }}$ contenidas en el citado inciso del artículo. Además, el accionante pretendió que, en forma subsidiaria, es decir, en caso de no declararse inconstitucionales tales expresiones, se condicionara su constitucionalidad al entendimiento de que la solución de las consultas por parte de la Administración no excluía la responsabilidad patrimonial del Estado que llegare a surgir. Así pues, para el demandante, las referidas palabras eran contrarias a los artículos 2, 6 y 90 de la Constitución Política, en la medida en que implicaban un desequilibrio en las cargas públicas de los particulares y una exoneración injustificada de responsabilidad para el Estado.

Tras analizar el papel del derecho de petición en el Estado social y democrático de Derecho y de explicar que la formulación de consultas a las autoridades hace parte del ejercicio de este derecho fundamental -consultas que, según es sabido, tienen como finalidad que se expida un concepto sobre una materia-, la Corte Constitucional señala que los conceptos, en principio, no pueden asimilarse a los actos administrativos, ya que no producen efectos jurídicos. Esto, por cuanto, 
[e]l acto administrativo representa el modo de actuar ordinario de la administración y se exterioriza por medio de declaraciones unilaterales o bien orientadas a crear situaciones jurídicas generales, objetivas y abstractas o bien orientadas a crear situaciones concretas que reconocen derechos o imponen obligaciones a los administrados. (Corte Constitucional de Colombia, 2005, [en línea])

En cambio, "[l]os conceptos no configuran, en principio, decisiones administrativas pues no se orientan a afectar la esfera jurídica de los administrados, esto es, no generan deberes u obligaciones ni otorgan derechos" (Corte Constitucional de Colombia, 2005, [en línea]), pues el interesado puede elegir si los acoge o no. Ahora bien, según la Corte, tales conceptos pueden considerarse actos administrativos, si resultan obligatorios para sus destinatarios o para terceros, como lo expresó este alto tribunal en la Sentencia C-487 de 1996.

Con fundamento en estas ideas, la Corte llega a la conclusión de que los conceptos emitidos por las autoridades para resolver las consultas formuladas por las personas, de conformidad con el artículo 25 del Decreto 01 de 1984, no son actos administrativos, pues no gozan de carácter vinculante, salvo que produzcan efectos jurídicos, como sucede con los conceptos de la Subdirección Jurídica de la Dirección de Impuestos y Aduanas Nacionales. Sin embargo, la Corte admite, acudiendo a un criterio material, que si la persona que hace la petición no especifica si se trata de una petición ordinaria, de información o de consulta, se debe examinar el contenido de la respuesta que le brinda la autoridad, para poder determinar si esta constituye o no un acto administrativo.

En consecuencia, la Corte niega las pretensiones de la demanda, bajo el entendido de que no resulta violatorio de los artículos 2, 6 y 90 de la Constitución Política que el legislador establezca que los conceptos expedidos por la Administración al resolver consultas no son de obligatorio cumplimiento, ni comprometen la responsabilidad del Estado, ya que el carácter no vinculante de dichos conceptos no significa que las autoridades puedan actuar de modo arbitrario -si lo hacen, entonces deben responder- $\mathrm{y}$, además, no es conveniente establecer de modo general una responsabilidad patrimonial del Estado por la emisión de tales recomendaciones, sugerencias o pautas de conducta, porque podría 
afectarse el canal de comunicación entre las personas y la Administración, que representan las consultas.

Se destaca, pues, cómo en este pronunciamiento la Corte Constitucional expresa que para poder hablar de acto administrativo es indispensable que exista una decisión -lo que excluye, en principio, las sugerencias, recomendaciones $\mathrm{u}$ orientaciones en que consisten los conceptos de la Administración, ya que estos no deciden algo-, y que dicha declaración produzca efectos jurídicos, es decir, genere un derecho o una obligación que torne obligatorio el acto. Bajo esta óptica, reitera que si el concepto, a pesar de no contener una decisión, obliga de algún modo, se convierte en un acto administrativo, aunque mejor sería afirmar que, en realidad, nunca fue un concepto, sino un acto administrativo, salvo que se admita la posibilidad de que puede ser concepto para algunos destinatarios y acto administrativo para otros.

\section{Sentencia C-173/2006: el dictamen previo y favorable que se expide como requisito para la toma de la decisión hace parte de un acto administrativo complejo}

Un año después, la Corte conoció la demanda de inconstitucionalidad parcial presentada contra el artículo 32 de la Ley 643 de 2001, "[p]or la cual se fija el régimen propio del monopolio rentístico de juegos de suerte y azar". Específicamente, el aparte normativo demandado establecía que "[l]os juegos localizados que a partir de la sanción de la presente ley pretendan autorización de la Empresa Territorial para la Salud, ETESA, deberán contar con un concepto previo y favorable del Alcalde donde operará el juego" (Congreso de la República de Colombia, 2001, [en línea]). Para el accionante, este inciso era irrazonable, porque hacía depender la decisión de un órgano nacional del concepto previo y favorable de una autoridad territorial, lo que afecta la estructura del Estado, el principio de autonomía de las entidades descentralizadas territorialmente y por servicios, al igual que el principio de legalidad. Por tal razón, consideraba que se afectaban varios artículos de la Constitución, como el 1, el 6, el 124, el 209, el 210, entre otros.

La Corte efectúa una interpretación sistemática del enunciado normativo demandado, así como de la facultad del legislador para establecer 
y regular el monopolio rentístico en materia de juego y azar. Así mismo, explica la naturaleza de ETESA, como Empresa industrial y Comercial del Estado del orden nacional, acogiéndose a las consideraciones contenidas en la Sentencia C-1191 de 2001, que se pronunció sobre la constitucionalidad de la creación de esta entidad. De otro lado, la Corte estudia la naturaleza del concepto previo y favorable que la norma demandada exige por parte del alcalde y llega a la conclusión de que este apartado del artículo 32 de la Ley 643 de 2001 no vulnera la Constitución, porque el legislador cuenta con un amplio margen de configuración normativa para regular la materia. Además, expresa que tampoco es contrario a la Carta Política que la ley le confiera al alcalde la competencia de expedir un concepto favorable, anterior a la autorización que pretenda obtenerse de ETESA para que operen los juegos, porque este es la máxima autoridad de policía del municipio y, por tanto, es garante del orden público de la localidad; es decir que tampoco se menoscaba el principio de autonomía territorial. Así las cosas, la Corte declara la exequibilidad de la disposición normativa.

La pregunta es, entonces, ¿qué tipo de acto es el concepto previo y favorable que debe expedir el alcalde, como presupuesto para la autorización de los juegos por parte de ETESA? Según la Corte, dicho concepto "es un acto de contenido material, que debe contener consideraciones fácticas y jurídicas, y por ende, puede ser susceptible de ser controvertido judicialmente" (Corte Constitucional de Colombia, 2006, [en línea]). Como se observa, se trata de una definición ambigua, porque no lo llama explícitamente acto administrativo, pero sí le asigna un requisito que, por regla general, es propio del acto administrativo: su motivación. Además, le endilga un rasgo que también se predica de los actos administrativos y no de los conceptos: la posibilidad de demandarlos ante la Jurisdicción Contencioso-Administrativa.

Como "acto de contenido material", dicho concepto previo y favorable del alcalde hace parte, para la Corte Constitucional, de un "acto administrativo complejo", figura que define, citando al doctrinante argentino Manuel María Díez, como el que resulta "del concurso de voluntades de varios órganos de una misma entidad o de entidades públicas distintas, que se unen en una sola voluntad" (Corte Constitucional de Colombia, 2006, [en línea]). De ahí que para la Corte, el concepto del 
alcalde sea un elemento constitutivo de un acto complejo y uno una mera formalidad.

El concepto de acto administrativo complejo es sencillo de entender, como la expresión de una sola voluntad conformada por la manifestación de varios órganos de una misma entidad o de varias entidades, sin que por ello desaparezca la unilateralidad, como requisito de existencia del acto. $Y$, en efecto, ese es el tipo de acto administrativo que se deriva del inciso demandado del artículo 32 de la Ley 643 de 2001 : tanto el concepto previo y favorable del alcalde, como la autorización de ETESA conforman un solo acto administrativo, de manera que sin el concepto previo no puede haber autorización válida. Pero, nada obsta para que se presente solo uno de ambos, al margen de su validez. Por ejemplo, que se expida el concepto previo y favorable, pero luego no haya autorización, o que se decrete esta, pretermitiéndose el concepto. En el primer caso habría un concepto que, por sí solo, no podría obrar como título habilitante de la actividad (iun acto administrativo incompleto?); en el segundo se estaría en presencia de un acto administrativo simple, viciado de nulidad, por haber sido expedido en forma irregular. Así pues, la sencillez de la definición del acto administrativo complejo no oculta la dificultad de las situaciones a las que, en la práctica, puede dar lugar.

De los comentarios de la Corte podría considerarse que el concepto previo y favorable del alcalde, analizado individualmente, es un acto administrativo que se integra a un acto administrativo complejo, pues para aquella debe ser motivado y es demandable judicialmente.

\section{La inexistencia de un concepto claro y unívoco de acto administrativo en la jurisprudencia de la Corte Constitucional}

Con fundamento en las providencias comentadas, se puede afirmar que en la jurisprudencia de la Corte Constitucional no existe un concepto claro y unívoco de acto administrativo. Lo primero, porque, como se advierte, las nociones citadas no permiten comprender en forma diáfana la noción, con todo su alcance. En otras palabras, no queda claro si para que un acto de la Administración pueda considerarse acto administrativo 
debe ser una declaración o manifestación solo de voluntad (dado que, en algunas sentencias, la Corte también admite las declaraciones de conocimiento o de deseo). A su vez, tampoco se sabe certeramente si los actos de trámite son para la Corte actos administrativos y en qué casos los conceptos adquieren tal categoría.

La segunda afirmación, referida a la ausencia de un concepto unívoco de acto administrativo en la jurisprudencia de la Corte, se asienta en la evidencia -que pudo observarse- de que este alto tribunal ha acudido a varias nociones doctrinarias de acto administrativo, como las de Georges Vedel, Manuel María Díez, Eduardo García de Enterría y Tomás-Ramón Fernández, pero no se ha decantado por una en específico, que mantenga a lo largo de los años. Sin embargo, puede señalarse que la de Eduardo García de Enterría y Tomás-Ramón Fernández ha sido la definición más utilizada por la Corte Constitucional. Aun así, tampoco ha existido uniformidad en la aplicación de esta noción, porque, como se indicó, para los mencionados profesores españoles los actos administrativos son declaraciones de voluntad, de juicio, de conocimiento o de deseo, que se profieren en ejercicio de una función administrativa, distinta de la potestad reglamentaria. Sin embargo, para la Corte Constitucional, en primer lugar, no toda manifestación de conocimiento o de deseo de la Administración es un acto administrativo - por eso, por regla general, les niega este carácter a los conceptos-, sino solo cuando resulta obligatoria, por contener una decisión que crea, modifica o extingue una situación jurídica. En segundo lugar, según se anotó, la Corte también ha indicado que los reglamentos son actos administrativos, con lo que niega aquello de que la potestad reglamentaria no pueda dar lugar a la expedición de este tipo de actos.

Ahora bien, cabe preguntarse si de la Constitución se debe o se puede derivar la existencia de un significado correcto del acto administrativo. Al respecto, se considera que no, pues si el constituyente no lo consagró, es viable afirmar que las ocasiones en las que la Constitución utiliza el término "acto administrativo" o "actos administrativos", alude a un concepto jurídico indeterminado, que los operadores jurídicos deben determinar en cada caso. Para este propósito, la jurisprudencia y la doctrina actúan como criterios auxiliares en la construcción de una definición de acto administrativo; sin embargo, no hay elementos que permitan sostener 
que, a partir del contenido de la Constitución, haya per se definiciones admisibles e inadmisibles del acto administrativo, o que haya una más correcta que las otras.

Lo anterior no obsta para reconocer que, en ausencia de una definición de esta figura en el articulado constitucional, el legislador y el presidente de la República -el primero, en ejercicio de la libertad de configuración normativa, y el segundo, en virtud de la potestad reglamentaria- podrían definir por vía normativa la institución. De hecho, un intento, aunque desafortunado, de construcción de un concepto normativo de acto administrativo fue la redacción inicial del artículo 83 del Decreto 01 de 1984, ${ }^{2}$ posteriormente subrogado por el artículo 13 del Decreto 2304 de 1989 y derogado por el artículo 309 de la Ley 1437 de 2011. Dicha definición se ha calificado de excesivamente psicológica, porque condicionaba la existencia del acto administrativo a una conducta en la que influyera de modo directo e inmediato la voluntad o la inteligencia. Además, era imprecisa, porque asimilaba las operaciones y las vías de hecho administrativas a los actos administrativos.

Teniendo en cuenta, por tanto, que en la actualidad no existe una definición normativa del acto administrativo, las nociones jurisprudenciales y doctrinarias juegan un papel auxiliar en la interpretación de las disposiciones constitucionales, legales y reglamentarias que aluden al instituto del acto administrativo; lo que es acorde con lo señalado en el artículo 230 de la Constitución y, además, resulta medular en la construcción sistemática del Derecho administrativo.

2 Esta disposición establecía:

La actividad administrativa se cumple mediante actos o hechos y toda estará sujeta al control jurisdiccional en los términos previstos en la Constitución Política, en las leyes y en este Código.

Son actos administrativos las conductas y las abstenciones capaces de producir efectos jurídicos, y en cuya realización influyen de modo directo e inmediato la voluntad o la inteligencia. Son hechos administrativos los acontecimientos y las omisiones capaces de producir efectos jurídicos, y en cuya realización no influyen de modo directo e inmediato la voluntad o la inteligencia.

Las llamadas "operaciones administrativas" y "vías de hecho" se considerarán, en adelante y para todos los efectos, actos administrativos. 


\section{El correlato de los significados del acto administrativo construidos por la Corte Constitucional en las definiciones del Consejo de Estado y de la doctrina especializada}

La falta de univocidad del concepto de acto administrativo en la jurisprudencia de la Corte Constitucional ha tenido su correlato en la similar ambigüedad con la que el Consejo de Estado y la doctrina especializada han definido dicha institución.

En efecto, tampoco al interior del Consejo de Estado -máximo tribunal de la Jurisdicción que ostenta la cláusula general de competencia para el control de juridicidad de los actos administrativos- se encuentra una noción uniforme de dicha forma de conducta de las autoridades, sino que, por el contrario, diversas providencias de esta corporación reflejan la misma ausencia de acuerdo en relación con la definición de tal concepto.

A modo enunciativo - teniendo en cuenta que el tema del presente artículo es, principalmente, el análisis de los significados del acto administrativo en la jurisprudencia de la Corte Constitucional-, y con la finalidad de demostrar la afirmación hecha con anterioridad, a continuación se mencionan algunas de las definiciones del acto administrativo expuestas por el Consejo de Estado.

Este alto tribunal ha precisado que "no todo acto de la administración es un acto administrativo" (Consejo de Estado, 2016), ${ }^{3}$ puesto que, desde su perspectiva, existen declaraciones intelectuales de la Administración, que no siempre están dirigidas a producir efectos jurídicos, es decir, a crear, modificar o extinguir derechos y obligaciones. Por tanto, según lo indicó la Sección Segunda en un auto reciente, dicha corporación, en reiteradas oportunidades, ha expresado que "el acto administrativo es toda manifestación de voluntad de una entidad pública o de un particular en ejercicio de funciones públicas, capaz de producir efectos jurídicos" (Consejo de Estado, 2018). ${ }^{4}$ Ahora bien, esta no ha sido una postura uniforme en la jurisprudencia contencioso-administrativa, pues otros pronunciamientos del Consejo de Estado han predicado significados diferentes. Así, por ejemplo, en algunas providencias, adoptando la noción del doctrinante y ex-consejero

\footnotetext{
3 C.P. Martha Teresa Briceño de Valencia (E).

4 C.P. Rafael Francisco Suárez Vargas.
} 
de Estado Jaime Orlando Santofimio Gamboa, este alto tribunal indicó que el acto administrativo es "toda manifestación unilateral, por regla general de voluntad, de quienes ejercen funciones administrativas, tendiente a la producción de efectos jurídicos" (Consejo de Estado, 2018); ${ }^{5}$ con lo cual dejó abierta la posibilidad de que el acto administrativo, excepcionalmente, consista en una manifestación de algo distinto a la voluntad, como también lo admitió en sentencia del 14 de junio de 2018, cuando afirmó que el contenido del acto administrativo puede ser una opinión o concepto, es decir, no necesariamente una voluntad decisoria (Consejo de Estado, 2018). ${ }^{6}$ De otro lado, también planteó que ciertos actos proferidos por autoridades que ejercen actividades mercantiles no son actos administrativos, sino actos de derecho privado (Consejo de Estado, 2018); ${ }^{7}$ lo que es bastante problemático, porque, si la noción que ha acogido desde hace años el Consejo de Estado es que el acto administrativo es una manifestación o declaración proferida en ejercicio de la función administrativa, debería serlo, independientemente del régimen jurídico aplicable a tal decisión. Por tanto, que el acto se rija por el Derecho privado, no debería quitarle su naturaleza de acto administrativo.

La situación en la doctrina no es más esperanzadora, si se busca un concepto unívoco del acto administrativo, pues en las obras nacionales y extranjeras que han alcanzado mayor notoriedad sobre el tema, dicha institución se define en forma disímil. Así, por ejemplo, mientras algunos doctrinantes consideran que el acto administrativo es una manifestación (Rodríguez, 2015, p. 331), otros dicen que es una declaración (Dromi, 2000, p. 16); mientras algunos piensan que la unilateralidad es consustancial a la definición del acto administrativo (Gordillo, p. IX-7), otros creen que es accidental, porque también puede consistir en un acuerdo, o sea, admiten que pueda ser bilateral (Marienhoff, 1983, p. 39); mientras algunos plantean que el objeto de la declaración (o manifestación -por lo que se indicó anteriormente-) es solo la voluntad (Díez, 1961, p. 108), otros expresan que puede ser también el juicio, el conocimiento o el de- 
seo (García de Enterría \& Fernández, 2008, p. 526), y mientras algunos incluyen el reglamento dentro de la definición del acto administrativo (Santofimio, 2017, p. 551), otros lo excluyen (Bocanegra, 2006, p. 34).

Si bien la definición del acto administrativo más admitida en el ordenamiento jurídico colombiano es aquella que afirma que se trata de una manifestación unilateral de voluntad proferida en ejercicio de función administrativa, no ha sido, pues, la única noción doctrinaria que se ha elaborado.

Lo anterior deja en evidencia que la falta de uniformidad en los significados del acto administrativo contenidos en la jurisprudencia de la Corte Constitucional es una manifestación específica de la falta de claridad de dicha noción en la doctrina jurídico-administrativa y en la jurisprudencia del Consejo de Estado, o sea, su correlato.

\section{La competencia para la definición normativa y jurisprudencial del acto administrativo en Colombia}

Si, como se argumentó, de la Constitución Política de 1991 no se deriva la existencia de un concepto de acto administrativo y la Corte Constitucional ha acudido a distintas nociones, ¿quién goza de competencia para definir dicha forma de ejercicio de la función administrativa?

El artículo 150 de la Constitución le asigna al Congreso de la República la cláusula general de configuración legislativa. Por su parte, el artículo 189, numeral 11 de la Carta le confiere al presidente de la República la potestad reglamentaria para garantizar la cabal ejecución de la ley. Ambos enunciados normativos operan, entonces, como fundamento normativo de la idea según la cual el Congreso y el presidente de la República gozan de competencia normativa para definir el acto administrativo. Dicho de otro modo, si alguna de estas autoridades quisiera establecer normativamente el alcance de dicho concepto, lo podría hacer, pero ¿qué tan deseable o pertinente sería?

Un ejercicio de Derecho comparado refleja que, por ejemplo, en Alemania se definió el acto administrativo por vía normativa. En efecto, el artículo 35 de la Ley Alemana de Procedimiento Administrativo estableció que "acto administrativo es toda disposición, resolución u otra 
medida de autoridad adoptada por un órgano administrativo y dirigida a la regulación de un caso particular en el ámbito del Derecho público, con efectos inmediatos en el exterior (frente a terceros)" (Bocanegra, 2006, p. 33).

También, como se indicó anteriormente, en Colombia se consagró un significado concreto del acto administrativo en el artículo 83 del Decreto 01 de 1984, ya derogado, disposición que expresaba, en lo que conviene destacar: "Son actos administrativos las conductas y las abstenciones capaces de producir efectos jurídicos, y en cuya realización influyen de modo directo e inmediato la voluntad o la inteligencia" (Gobierno de la República de Colombia, 1984, [en línea]).

Tales ejemplos demuestran que, de existir voluntad política, el acto administrativo podría definirse por vía normativa, pero esta es una labor compleja, que genera el riesgo de petrificar el significado de la figura en una fuente formal del Derecho; significado que podría no gozar de legitimidad para aquellos que no compartan la noción construida en la ley o en el reglamento. Lo último se debe a que, como se expuso, el acto administrativo es una institución que ha gozado de tantas definiciones doctrinarias y jurisprudenciales, que resulta ilusorio pensar que una noción normativa del mismo sería aceptada por todos los estudiosos y operadores jurídicos. Entonces, tal como sucedió con el citado artículo 83 del Decreto 01 de 1984, lo más probable es que una eventual definición legal o reglamentaria del acto administrativo sería altamente criticada por los sectores doctrinarios o jurisprudenciales que lleguen a considerar que tal concepto carece de rigurosidad científica, que resulta inexacto, poco técnico, o la rechacen, utilizando argumentos de similar naturaleza. Dicha actitud podría, o bien hacer que la noción tenga poca vocación de permanencia o que vaya tornándose ineficaz.

Por otra parte, conforme al artículo 230 de la Constitución Política, la jurisprudencia, como criterio auxiliar, puede también -como, de hecho, lo ha venido realizando- estructurar nociones sobre el acto administrativo. Tal idea asume más sentido en la actualidad, ya que, desde la expedición de la Ley 1437 de 2011,8 el precedente contenido en las sentencias de unificación jurisprudencial del Consejo de Estado tiene

8 Al respecto, pueden consultarse los artículos 10, 102, 269 y siguientes de esta ley. 
fuerza vinculante, tanto frente a las autoridades administrativas como a las jurisdiccionales. Ello sin perjuicio de la aplicación obligatoria del precedente derivado de las sentencias de la Corte Constitucional, como esta corporación lo sostuvo en las sentencias C-836/01 (M.P. Rodrigo Escobar Gil) y C-634/11 (M.P. Luis Ernesto Vargas Silva), entre otras. Así pues, por esta vía, la noción de acto administrativo que se estableciera también tendría efectos vinculantes.

Lo expresado permite inferir que si bien una noción normativa o jurisprudencial del acto administrativo es posible -ya que el legislador y la autoridad reglamentaria por excelencia, tienen competencia para confeccionarla-, no por ello sería deseable o pertinente. Tal definición solo podría considerarse conveniente si guarda coherencia con el significado más aceptado en la práctica y en la ciencia del Derecho administrativo; lo que no obsta para que dicha noción pueda ser modificada en el futuro, respondiendo a la evolución de los conceptos en el ordenamiento jurídico.

\section{La utilidad práctica de una noción clara del acto administrativo}

La existencia de un concepto claro y, en la medida de lo posible, unívoco, del acto administrativo reporta grandes ventajas en la aplicación del Derecho. En primer lugar, la definición del acto administrativo es una actividad esencial en la consolidación científica del Derecho administrativo, desde una perspectiva sistemática (Schmidt-Assman, 2003, pp. 1-50), porque permite identificar y establecer los contornos de una de las principales figuras de esta área jurídica. En segundo lugar, el conocimiento del significado del acto administrativo otorga certidumbre a la actividad de las autoridades, porque les permite saber en qué eventos su conducta puede calificarse con dicho nombre y en qué casos actúan de otra manera, expidiendo actos de la administración que no tengan un carácter decisorio -informes, opiniones, certificaciones, etc.-, o ejecutando hechos administrativos, omisiones administrativas, operaciones administrativas, vías de hecho administrativas y contratos estatales. Los

presupuestos y consecuencias de cada una de estas formas de ejercicio de 
la función administrativa son, como se sabe, distintos. Así, por ejemplo, mientras que, para celebrar un contrato se requiere siempre del consentimiento entre dos sujetos y del cumplimiento de normas especiales que el ordenamiento prevé para el perfeccionamiento de tales negocios, ${ }^{9}$ la expedición del acto administrativo -por lo menos, según el concepto más admitido-, al ser unilateral, no requiere de un acuerdo de voluntades. En tercer lugar, la definición del acto administrativo también garantiza el derecho de defensa y el libre acceso a la administración de justicia de las personas. Esto en la medida en que existen mecanismos de control administrativos y judiciales que solo operan respecto de los actos administrativos, verbigracia los recursos en sede administrativa, ${ }_{10}^{10}$ la revocación directa $^{11}$ y los medios de control judicial anulatorios: nulidad simple, ${ }^{12}$ nulidad y restablecimiento del derecho, ${ }^{13}$ nulidad electoral, ${ }^{14}$ entre otros. Por consiguiente, conocer el significado del acto administrativo permite al destinatario de la medida saber a través de qué instrumentos jurídicos puede cuestionar su legalidad o conveniencia, de qué manera debe computar el término de caducidad de la acción ${ }^{15} \mathrm{y}$, en general, calcular los efectos de la decisión y sus posibilidades de defensa frente a la misma, evitando que le rechacen sus actuaciones bajo el argumento de que lo atacado no es un acto administrativo. En cuarto lugar, otras instituciones del procedimiento administrativo están configuradas con base en el acto administrativo o solo aplican frente a este, como la notificación, ${ }^{16}$

9 Artículo 41 de la Ley 80 de 1993.

10 Según el artículo 74 de la Ley 1437 de 2011, los recursos proceden contra los actos administrativos.

11 Ello, de conformidad con los artículos 93 al 97 de la Ley 1437 de 2011 que prevén la revocación directa como un mecanismo contra los actos administrativos; no respecto de otras formas de ejercicio de la función administrativa.

12 Artículo 137 de la Ley 1437 de 2011.

13 Artículo 138 de la Ley 1437 de 2011.

14 Artículo 139 de la Ley 1437 de 2011.

15 El artículo 164 de la Ley 1437 de 2011 establece términos de caducidad específicos para el cuestionamiento de la legalidad de los actos administrativos. Por ejemplo, si se trata de la pretensión de simple nulidad de un acto administrativo, la demanda puede presentarse en cualquier tiempo, lo mismo que si se dirige contra a un acto administrativo ficto o presunto, pero, para el medio de control de nulidad y restablecimiento del derecho hay términos específicos -de 4 meses, 30 días, etc.-

16 El artículo 66 de la Ley 1437 de 2011 prevé que "los actos administrativos de carácter particular deberán ser notificados en los términos establecidos en las disposiciones siguientes". 
la presunción de legalidad, ${ }^{17}$ la ejecutoriedad ${ }^{18}$ y el control por vía de excepción, ${ }^{19}$ lo que pone de manifiesto la importancia dogmática de un concepto decantado de dicha institución.

Con lo anterior no se quiere indicar que el acto administrativo sea actualmente en nuestro sistema normativo la única conducta administrativa que permita un control jurisdiccional efectivo y que, por ello, deba definirse con precisión. Desde hace décadas el proceso judicial contenciosoadministrativo no se considera ya un simple proceso al acto, sino que se dirige a toda forma de conducta administrativa. Ello explica la existencia de varios medios de control, algunos de los cuales -como el de reparación directa o el de grupo- no buscan la nulidad de acto administrativo alguno, sino la reparación integral del daño antijurídico ocasionado por actuaciones materiales u omisivas de la Administración.

Pero la pérdida gradual de protagonismo del acto administrativo en el Derecho administrativo contemporáneo -cada vez más influenciado por nuevos modelos de gobernanza, que hacen de la participación ciudadana una premisa esencial y de la búsqueda de consensos la condición de legitimidad de las políticas públicas, más allá de la clásica imposición unilateral (Barnés, 2011, pp. 90-108) - no puede implicar una renuncia a su adecuada definición, pues el acto administrativo continúa cumpliendo una función dogmática en el procedimiento administrativo y en el proceso contencioso administrativo, como se explicó.

Ahora bien, el significado del acto administrativo no puede construirse a partir de disquisiciones conceptuales abstractas, desconectadas de los usos sociales. Por el contrario, debe definirse según la forma como los operadores jurídicos -la Administración, los jueces, los profesionales del Derecho y, en general, la sociedad- entienden esta noción. He aquí el reto de las altas cortes y de la doctrina del Derecho administrativo.

17 Este es un atributo del que solo gozan los actos administrativos, según el artículo 88 de la Ley 1437 de 2011.

18 Este es también un rasgo propio de los actos administrativos, al tenor del artículo 89 de la Ley 1437 de 2011.

19 Figura prevista en el artículo 148 de la Ley 1437 de 2011 y que permite la inaplicación de un acto administrativo por contravención de la legalidad. 


\section{Conclusiones}

a. La Corte Constitucional no ha sostenido una postura uniforme en lo que respecta a la definición del acto administrativo, pues en algunas ocasiones ha planteado que se trata de una declaración de voluntad, pero en otras ha admitido que también las manifestaciones de conocimiento o de deseo pueden constituir actos administrativos. Por otro lado, no existe una tesis consistente acerca de si los actos de trámite son o no actos administrativos.

b. Para el alto tribunal, los conceptos, por regla general, no son actos administrativos, pero en algunos casos pueden llegar a serlo, cuando resultan vinculantes para sus destinatarios, por crear, modificar o extinguir derechos u obligaciones. Sin embargo, en otros supuestos la Corte ha considerado los conceptos previos como "actos de contenido material" que pueden integrar un "acto administrativo complejo", sin precisar si en tales eventos el concepto es una formalidad previa o un acto administrativo.

c. A pesar de que la Corte ha acogido definiciones doctrinales extranjeras del acto administrativo, no las admite por completo. Así, por ejemplo, no obstante que acepta el concepto de Eduardo García de Enterría y Tomás-Ramón Fernández, según el cual el acto administrativo es una declaración de voluntad, de juicio, de conocimiento o de deseo, no comparte lo que estos autores expresan, en el sentido de que el acto debe ser proferido en ejercicio de una función administrativa distinta de la potestad reglamentaria, pues para la Corte los reglamentos son actos administrativos.

d. Si bien la Corte Constitucional ha construido o aceptado nociones doctrinarias del acto administrativo, esto no significa que de la Constitución se pueda extraer una noción "correcta" de este, que deba gobernar la interpretación de las disposiciones superiores que utilizan dicha expresión. Así pues, el acto administrativo es un concepto jurídico indeterminado consagrado en la Constitución. Por ello, el legislador, en ejercicio de su libertad de configuración normativa, el presidente de la República, en uso de su potestad reglamentaria, la Corte Constitucional y el Consejo Estado, pueden definir el acto 
administrativo, proyecto que no siempre es afortunado, como lo muestra la redacción inicial del artículo 83 del Decreto 01 de 1984.

e. Ante la ausencia de una definición normativa del acto administrativo, la jurisprudencia y la doctrina juegan un papel trascendental en tanto criterios auxiliares de interpretación, para llenar el vacío constituido por la falta de un concepto de dicha institución. Incluso, puede afirmarse que la construcción de un significado del acto administrativo, en las obras académicas y en las decisiones judiciales, es una importante fuente material para un correcto entendimiento de esta figura, acorde con los desarrollos teóricos del Derecho administrativo y con lo que en la práctica se entiende por dicha forma de actuación de las autoridades.

\section{Referencias}

\section{Normativa}

Constitución Política de Colombia [Const.] (20, julio, 1991). [en línea]. Gaceta Constitucional No. 116.

Congreso de la República de Colombia. (24, agosto, 1887). Que adiciona y reforma los Códigos nacionales, la ley 61 de 1886 y la 57 de 1887. [Ley 153 de 1887]. Diario Oficial No. 7.151.

Congreso de la República de Colombia. (20, agosto, 1913). Sobre régimen político y municipal. [Ley 4 de 1913]. Diario Oficial No. 15.012.

Gobierno de la República de Colombia. (2, enero, 1984). Por el cual se reforma el Código Contencioso Administrativo. [Decreto 01 de 1984]. Diario Oficial No. 36.439 .

Gobierno de la República de Colombia. (15, julio, 1986). Por el cual se adopta el Código Electoral. [Decreto 2241 de 1986]. Diario Oficial No. 37.571.

Congreso de la República de Colombia. (28, octubre, 1993). Por la cual se expide el Estatuto General de Contratación de la Administración Pública. [Ley 80 de 1993]. Diario Oficial No. 41.094.

Congreso de la República de Colombia. (29, julio, 1997). Por la cual se desarrolla el artículo 87 de la Constitución Política. [Ley 393 de 1997]. Diario Oficial No. 43.096 . 
Congreso de la República de Colombia. (16, enero, 2001). Por la cual se fija el régimen propio del monopolio rentístico de juegos de suerte y azar. [Ley 643 de 2001]. Diario Oficial No. 44.294.

Congreso de la República de Colombia. (18, enero, 2011). Por la cual se expide el Código de Procedimiento Administrativo y de lo Contencioso Administrativo. [Ley 1437 de 2011]. Diario Oficial No. 47.956.

\section{Jurisprudencia}

\section{Corte Constitucional}

Corte Constitucional. Sentencia C-487/1996 (M.P. Antonio Barrera Carbonell). Corte Constitucional. Sentencia C-638/2000 (M.P. Vladimiro Naranjo Mesa). Corte Constitucional. Sentencia C-037/2000 (M.P. Vladimiro Naranjo Mesa). Corte Constitucional. Sentencia C-1436/2000 (M.P. Alfredo Beltrán Sierra).

Corte Constitucional. Sentencia C-836 /2001 (M.P. Rodrigo Escobar Gil).

Corte Constitucional. Sentencia C-620/2004 (M.P. Jaime Araújo Rentería).

Corte Constitucional. Sentencia C-542/2005 (M.P. Humberto Antonio Sierra Porto).

Corte Constitucional. Sentencia C-173/2006 (M.P. Humberto Antonio Sierra Porto).

Corte Constitucional. Sentencia T-945 de 2009 (M.P. Mauricio González Cuervo). Corte Constitucional. Sentencia C-634 de 2011 (M.P. Luis Ernesto Vargas Silva). Corte Constitucional. Sentencia SU-617 de 2014 (M.P. Nilson Pinilla Pinilla). Corte Constitucional. Sentencia T-533 de 2014 (M.P. Luis Guillermo Guerrero Pérez).

Corte Constitucional. Sentencia T-412 de 2017 (M.P. Gloria Stella Ortiz Delgado).

\section{Consejo de Estado}

Consejo de Estado. Sala de lo Contencioso Administrativo. Sección Cuarta. C.P.: Martha Teresa Briceño de Valencia (E). Auto del $1^{\circ}$ de agosto de 2016. Rad: 25000-23-37-000-2013-01352-01 (22048).

Consejo de Estado. Sala de lo Contencioso Administrativo. Sección Tercera. Subsección B. C.P.: Ramiro Pazos Guerrero. Sentencia del 14 de junio de 2018. Rad.: 80001-23-31-003-1994-08640-01 (39220). 
Consejo de Estado. Sala de lo Contencioso Administrativo. Sección Tercera. Subsección C. C.P.: Jaime Orlando Santofimio Gamboa. Auto del 19 de junio de 2018. Rad: 25000-23-36-000-2017-01974-01 (61132).

Consejo de Estado. Sala de lo Contencioso Administrativo. Sección Segunda. Subsección "A". C. P.: Rafael Francisco Suárez Vargas. Auto del 6 de diciembre 2018. Rad.: 68001-23-33-000-2017-00669-01(4446-17).

Consejo de Estado. Sala de lo Contencioso Administrativo. Sección Tercera. Subsección C. C.P.: Jaime Enrique Rodríguez Navas. Auto del 27 de febrero de 2019. Rad.: 08001-23-33-000-2017-01056-01 (61534).

\section{Doctrina}

Barnés, J. (2011). Tres generaciones del procedimiento administrativo. Derecho PUCP. Revista de la Facultad de Derecho, (67), 77-108.

Bocanegra Sierra, R. (2005). La teoría del acto administrativo. Madrid: Iustel.

Bocanegra Sierra, R. (2006). Lecciones sobre el acto administrativo. Navarra: Thomson-Civitas.

Díez, M. (1961). El acto administrativo (Segunda edición). Buenos Aires: Tipográfica Editora Argentina.

Dromi, R (2000). El acto administrativo. Buenos Aires: Ciudad Argentina.

García de Enterría, E. (2007). Las transformaciones de la justicia administrativa: de excepción singular a la plenitud jurisdiccional. ¿Un cambio de paradigma? Madrid: Thomson-Civitas.

García de Enterría, E. E Fernández, T. (2008). Curso de Derecho administrativo. Tomo I. Bogotá, Lima: Temis, Palestra.

Gordillo, A. (2014). Tratado de Derecho administrativo Tomo 9. Primeros Manuales. Buenos Aires: Fundación de Derecho administrativo.

Marienhoff, M. (1983). Tratado de Derecho administrativo Tomo III-A. Contratos administrativos. Buenos Aires: Abeledo-Perrot.

Rodríguez, L. (2015). Derecho administrativo. General y colombiano (19ª Ed.). Bogotá: Temis.

Santofimio, J. (2017). Compendio de Derecho administrativo. Bogotá: Universidad Externado de Colombia.

Schmidt-Assmann, E (2003). La teoría general del Derecho administrativo como sistema. Objeto y fundamentos de la construcción sistemática. Madrid: Marcial Pons, Instituto Nacional de Administración Pública. 